\title{
Content creation and distribution in the digital single market
}

\section{Colin Blackman}

Colin Blackman is

Directorat Camford

Associates Ltd,

Cambridge, UK.
Received 15 July 2016 Revised 15 July 2016

Accepted 18 July 2016

\section{Introduction}

Online content and carriage have always been interlocked. Yet, the current electronic communications markets and policy are tested by the sheer abundance of online content and its need for distribution through multiple channels and regardless of frontiers. Access to a wide variety of relevant content is key to democracy and the exercise of fundamental rights, just as the freedom to express oneself and disseminate and access content irrespective of means of communication is fundamental for pluralism. Moreover, content creation, distribution and consumption are increasingly occupying a crucial role for the success of online business and European competitiveness on the internet. Besides authors and media companies, internet users also increasingly generate content, which in turn contributes to the richness of diverse information available to European citizens, and beyond.

The more access to content becomes valuable, the greater the stakes in securing a prominent role in the selection and distribution of content, especially in the online environment. The presence of network externalities and centripetal forces on the internet, coupled with a relatively favourable regulatory environment in many legal systems that grants a menu of safe harbours to online intermediaries, has led many online intermediaries to occupy a remarkably large space in the internet ecosystem. These new powerful players have come to disrupt and also replace traditional publishers and content distributors as the real intermediaries between content producers and consumers.

To European Union (EU) policy makers, such trends can be ambiguous either representing the disruptive forces of competition or as indicators for new points of control in the internet ecosystem. Some commentators and policy makers argue that structural, aggressive policy measures are needed, from network neutrality to platform regulation, and antitrust interventions such as even breaking up large intermediaries to limit their ability to capitalize on their vertical and conglomerate integration. Others argue that the new online intermediaries represent a welcome disruptive innovation that should be allowed and enabled, as they bring further benefits to consumers, and as they introduce innovative business models such as personalized services and predictive algorithms.

The European Commission recently acknowledged in its digital single market strategy the growing importance of creating a fertile environment for content creation and distribution. Priority has therefore been given to content-related policy initiatives such as reforming copyright law, evaluating the "fitness" of legislation on audiovisual media services, and taking action against detrimental geoblocking practices that limit cross-border access to content. At the same time, concerns about the role of intermediaries are being tackled through antitrust investigations and sectoral inquiries (e.g. on e-commerce), and also through public consultations. These efforts are ushering in a new wave of policy measures 
aimed at ensuring that the digital single market is increasingly a place in which content can be created, funded and flow seamlessly across countries, in a way that stimulates the interests of creators while giving access to diverse contents to end users.

This was the context for EuroCPR 2016, organized and hosted by the Centre for European Policy Studies in Brussels on 14-15 March 2016. The conference was organized around several subthemes - perspectives on the distribution infrastructure: deployment and regulation; users and uses: an active role in making and breaking media policy; media and markets: new dynamics and changing technology; and getting media regulation right - and attracted wide variety of papers on many aspects of content creation and distribution in the EU[1].

In keeping with EuroCPR tradition, papers were discussed by academic and industry experts. The conference was complemented by keynote presentations by Bruno Soria (NERA) on "A new regulatory framework for the digital ecosystem", and Alexandre de Streel (University of Namur) on "Towards a robust regulatory framework for the 21st century information society", and an Industry dialogue with Augusto Preta (ITMedia Consulting), Grégoire Polad (Association of Commercial Television in Europe) and Tobias McKenney (Google).

Following a review process, a selection of the best papers from EuroCPR 2016 are included in this special issue.

Jean Paul Simon's paper, "User generated content - users, community of users and firms: toward new sources of co-innovation?", deals with the role of users in the creation (or curation) and distribution of digital content. It assesses their potential role as co-innovators and follows the progressive creation of a new space for users, tracking its specific forms in each subsector of the media and content industries. It analyses the new "division of labour" between amateurs and professionals in the book publishing industry, the cinema and video industry, the music industry, the newspaper industry and the video games industry. Each subsector reveals a disruption in the production and circulation of new content.

Simon's original contribution shows how the entire value chain of content (production-distribution-consumption) has opened up. The volume of user-generated content (UGC) now being produced has led to a qualitative change, with novel ways for creators and consumers to interact, sometimes with consumers becoming fully fledged producers. At the very least, the UGC model adds another source of production, thereby increasing diversity. Self-publishing allows amateurs to disseminate their musical or written work, and to select the relevant regime for allowing access to their work, which may be free or paid.

New technologies are therefore enabling a new category of intermediaries to appear, e.g. the YouTubers. Some may transition into professional content creators, but not all will do so. And for the media industries, UGC provides a novel way to identify promising new authors, musicians and film producers.

In their paper on the "Shrinking core? Exploring the differential agenda setting power of traditional and personalized news media", Judith Moeller, Damian Trilling, Natali Helberger, Claes de Vreese and Kristina Irion explore the effects of personalized news use on the perceived importance of these issues for the "common core", i.e. a shared issue agenda within the public sphere. Such a common core provides democracies with a set of topics that structure the public debate. The advent of personalized news media that use smart algorithms to tailor the news offer to the user challenges the established way of setting the agenda of the common core of issues. In particular, the paper examines whether personalized news use leads to a concentration at the top of the issue agenda or to a more diverse issue agenda with a long tail of topics. Based on a cross-sectional survey of a representative population sample, the authors find that personalized news use does not lead to a small common core in which few topics are discussed extensively; yet, there is a relationship between personalized news use and a preference for less discussed topics. This is a result of a specific user profile of personalized news users: younger, more 
educated news users are more interested in topics at the fringes of the common core and also make more use of personalized news offers. The results are discussed in the light of media diversity and recent advances in public sphere research.

The paper by Katharine Sarikakis, Olga Kolokytha and Krisztina Rozgonyi on "Copyright (and) culture: the governance of audiovisual archives" is concerned with how new technologies and digitization have impacted incentives to creativity. More specifically, their paper seeks to understand the policy dynamics of copyright regulation for digital audiovisual archives in Europe and its potential impact. It examines the social relevance of archives, European cultural policies and the implementation of copyright policies through legal analysis of key EU legislation with direct relevance to the availability of and accessibility to digital historical content by European citizens. The authors juxtapose relevant cultural policy interventions with the corresponding legal rules and norms in copyright legislation, aiming to evaluate the ways in which normative arguments are reflected in these acts. They conclude that European copyright legislation has systematically fallen short of enabling European citizens to fully participate in the digital public space and access, enjoy and explore a significant part of their cultural heritage.

In their paper, "Another breach in the wall: copyright territoriality in Europe and its progressive erosion on the grounds of competition law", Felice Simonelli and Giuseppe Mazziotti show how the European Commission is seeking to solve the problems of market fragmentation and inaccessibility of copyright content in the digital single market. Their analysis draws on a still unresolved conflict between the enforcement of national copyright titles and the EU policy objective to ensure pan-European access to copyright works.

They first focus on the causal relationship between national copyright systems and the existing territorial partitions in online content markets. They then review the piecemeal approach followed by the Commission in its recent legislative initiative aimed at ensuring the cross-border portability of online content services. Simonelli and Mazziotti contrast this with the much more radical stance the Commission has taken in the ongoing antitrust case regarding the territorial partitions created by major film producers and the biggest EU broadcasters. In particular, the paper explains why the application of EU competition law to licensing agreements creating areas of absolute territorial exclusivity might have potentially disruptive effects on existing models of online distribution. The outcome will largely depend on how the ongoing antitrust case will be settled, but the paper concludes that the liberalization of so-called "passive sales" might force content owners and broadcasters (or content suppliers) to restructure markets for online content and to replace territoriality with other criteria that might help them differentiate their offerings and packages.

\section{Note}

1. Available at: www.eurocpr.org/programme_current.html

For instructions on how to order reprints of this article, please visit our website: www.emeraldgrouppublishing.com/licensing/reprints.htm

Or contact us for further details: permissions@emeraldinsight.com 